\title{
Predictors of Outcome in Neonates with Respiratory Distress
}

\author{
John BM ${ }^{1}$, Venkateshwar V², Dagar V
}

\begin{abstract}
Introduction: Many of the parameters utilised in scoring systems used to predict disease severity in respiratory distress in neonates are not readily available in the primary care facility of developing countries. This study was carried out to assess the utility of birth weight, gestational age, APGAR score at $5 \mathrm{~min}$, baseline oxygen saturation and Downe's score in prediction of requirement of respiratory support and mortality in neonates with respiratory distress. Material and Methods: A prospective study was carried out in the neonatal intensive care unit of a tertiary teaching hospital. 165 consecutively admitted neonates presenting with respiratory symptoms were included in the study. The relevant parameters and investigations were documented in a structured performa. The neonates were followed up for outcomes which included requirement of respiratory support and mortality. Results: A higher mortality was associated with birth weight of $\leq 1620$ grams, gestational age of $\leq 31$ weeks, APGAR score of $\leq 6$, Downe's score of $>3$ and baseline oxygen saturation of $\leq 86 \%$ ( $p$ values $<0.001$ ). The requirement of mechanical ventilation was more with birth weight of $\leq 2000$ grams, gestational age of $\leq 32$ weeks, APGAR score of $\leq 7$, Downe's score of $>4$ and baseline oxygen saturation of $\leq 87 \%$ ( $p$ value $<0.001$ ). The requirement of any respiratory support at 72 hours was associated with birth weight of $\leq 1894$ grams, gestational age of $\leq 37$ weeks, APGAR score of $\leq$ 7 , Downe's score of $>3$ and baseline oxygen saturation of $\leq 89 \%$ ( $p$-value $<0.001$ ). Conclusions: Readily available parameters like birth weight, gestational age, APGAR score, oxygen saturation and Downe's score could together be used to predict mortality and requirement of respiratory support in the resource limited setting.
\end{abstract}

Key words: Neonates, respiratory distress, respiratory support, predictors, outcome

\section{Introduction}

Despiratory distress is one of the commonest causes of admission Rof a neonate to the neonatal intensive care unit (NICU). It is a challenging problem and accounts for significant morbidity and mortality. In various Indian studies, it occurred in up to four to seven percent of the neonates ${ }^{1,2}$. There are various factors which
'Dr. BM John, Associate Professor (Paediatrics), Command Hospital (Air Force), Bangalore, India, ${ }^{2}$ Dr. V Venkateshwar, Professor (Paediatrics), Command Hospital (Air Force), Bangalore, India, ${ }^{3}$ Dr. Vinod Dagar, Paediatrician, Military Hospital, Danapur, Bihar, India.

Address for correspondence:

Dr. B M John, Associate Professor (Paediatrics), Command Hospital (Air Force),

Bangalore-560007, India

E-mail:drbmj1972@yahoo.com

Tel No: 09632483900

\section{How to cite}

John BM, Venkateshwar V, Dagar V. Predictors of Outcome in Neonates with Respiratory Distress. J Nepal Paediatr Soc 2015;35(1):31-37.

doi: http://dx.doi.org/10.3126/jnps.v35i1.11868

This work is licensed under a Creative Commons Attribution 3.0 License.

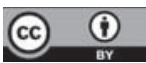

determine the progress and outcome in neonatal respiratory distress. The birth weight, gestational age and the degree of respiratory compromise are the key factors which decide the level of care the neonate would require. Clinical monitoring is most important as sophisticated equipments may 
not always be available in resource limited settings. Clinical scores such as Downe's score ${ }^{3}$, Silverman score $^{4}$, APGAR score $^{5}$ and ACoRN respiratory score ${ }^{6}$ are being used for assessing the severity of respiratory distress while CRIB (Clinical risk index for babies) ${ }^{7}$ and SNAPPE (Score for neonatal acute physiology-perinatal extension $)^{8}$ are being used for determining illness severity. Calculation of some of the above mentioned scores need estimation of fractional inspired oxygen, arterial blood gas analysis and monitoring of vitals including blood pressure. However, invasive monitoring and ventilator facilities are not available in all the neonatal care units. There is a dearth of studies on role of simple clinical parameters like Downe's score and pulse oximetry early on during the course of respiratory distress in predicting which neonates may have a higher mortality, need mechanical ventilation and need higher duration of respiratory support. Simple clinical scores if meticulously documented could be useful to determine the progression of the respiratory distress. This would then enable timely transfer of these neonates to higher centres from the primary neonatal care facility available in most of the developing countries.

This study was therefore conducted to assess the suitability of simple parameters like birth weight, gestation age, baseline oxygen saturation, APGAR score at five minutes and Downe's score as predictors of certain short term outcomes like requirement of respiratory support and mortality.

\section{Material and Methods}

Over a period of 18 months, all consecutively admitted neonates developing respiratory distress were studied. Inclusion Criteria: Neonates delivered in the hospital, which developed respiratory distress within 6 hours of birth, irrespective of gestational age and aetiology. Exclusion Criteria: All neonates admitted for indication other than respiratory distress and neonates with congenital anomalies.

Any newborn showing one or more of the following signs within 06 hours of birth was considered to have respiratory distress: (i) Respiratory rate of sixty per minute or more (ii) grunting (iii) intercostal or subcostal retraction (iv) cyanosis

Following data was recorded: Birth weight (babies were weighed as soon as possible after birth, nude, using standardized digital weighing scale), Gestational age (as per expected date of delivery (EDD) and confirmed by USG report mentioned in the antenatal follow up card), APGAR score at five minutes after birth,
Downe's score (at admission and after 2 hours, 6 hours, 12 hours and 24 hours), $\mathrm{SpO}_{2}$ at admission (in room air) and after 2 hours, 6 hours, 12 hours and 24 hours. Neonates in the study group were treated as per unit protocol which had specified indications for oxygen therapy, continuous positive airway pressure (CPAP), mechanical ventilation, surfactant therapy, antibiotics, fluid therapy, thermoregulation and supportive care. The neonates were followed up for the following outcomes: Need for mechanical ventilation at any stage during admission, Need for any respiratory support in the form of oxygen therapy, CPAP or mechanical ventilation at 72 hours after admission. Mortality and survival data was recorded at time of discharge.

For this study, neonates were divided into four groups based on their birth weight and gestational age for differential analysis as depicted in Table 1.

The diagnostic criteria for various causes of respiratory distress were adopted from the recommendations made by National Neonatology Forum and also published in National Neonatology Perinatology database report 2002-03 ${ }^{1}$.

Data analysis was done by using SPSS (Statistical package for social sciences) version 17.0. Fisher's exact test, Chi-square test, Odds ratios were used to find out the relationship between various parameters. Binary logistic regression analysis was used to find out the relationship between defined predictors and outcomes. Receivers Operating Characteristic curves were used to find the cut off values of the predictors for the specified outcomes. All the statistical tests were used at $95 \%$ confidence interval (C.I.) (5\% level of significance) and $p$-value of $<0.05$ was considered as a significant relation between studied parameters.

\section{Results}

During the study period, a total of 165 neonates having respiratory distress fulfilled the inclusion criteria of the study. They were followed up for studying the relationship between the specified predictors and the outcomes. The demographic profile of the studied population is depicted in Table 1.

In univariate analysis along with ROC curves : Birth weight $\leq 1620$ gram, gestational age of $\leq 31$ weeks, APGAR score of $\leq 6$, Downe's score of $>3$ and baseline oxygen saturation of $\leq 86 \%$ were found to be significantly associated with mortality (Table 2),

Birth weight $\leq 2000$ gram, gestational age of $\leq 32$ weeks, APGAR score of $\leq 7$, Downe's score of $>4$ and 
baseline oxygen saturation of $\leq 87 \%$ were significantly associated with requirement of mechanical ventilation (Table 3) . Birth weight $\leq 1894$ gram, gestational age of $\leq$ 37 weeks, APGAR score of $\leq 7$, Downe's score of $>3$ and baseline oxygen saturation of $\leq 89 \%$ were significantly associated with requirement of respiratory support $\left(\mathrm{O}_{2^{\prime}}\right.$ CPAP, mechanical ventilation) at $72 \mathrm{hrs}$ of life (Table 4).

On multivariate analysis by binary logistic regression, the following odds ratios were noted for various predictors:

Predictors versus mortality - Birth weight (OR1.002, 95\% Cl: 1.00-1.004), gestational age (OR0.60,95\% Cl: 0.42-0.86), APGAR score (OR-0.59,95\% Cl: 0.30-1.15), Downe's score at baseline (OR-1.42, 95\%
$\mathrm{Cl}$ : 0.85- 2.36) and oxygen saturation at baseline (OR$1.02,95 \% \mathrm{Cl}: 0.86-1.21)$.

Predictors versus mechanical ventilation- Birth weight (OR-0.99, 95\% Cl: 0.99- 1.00), gestational age(OR-1.33,95\% Cl: 1.06-1.67),APGAR score at 5 mins (OR-1.98,95\% Cl: 1.14-3.42), Downe's score at baseline (OR-0.87, 95\% Cl: 0.60-1.25) and oxygen saturation at baseline (OR-1.09, 95\% Cl: 0.97- 1.22).

Predictors versus respiratory support at 72 hoursBirth weight (OR-1.00, 95\% Cl: 0.99- 1.00), gestational age (OR-0.84, 95\% Cl: 0.71-1.01), APGAR score at 5 minutes (OR-0.76,95\% Cl: 0.48-1.19), Downe's score at baseline (OR-1.28, 95\% Cl: 0.96-1.72) and oxygen saturation at baseline (OR- $0.96,95 \% \mathrm{Cl}$ : 0.87- 1.07)

Table 1: Demographic characteristics of the studied population

\begin{tabular}{|c|c|c|c|}
\hline Variables & & Number & Percentage \\
\hline \multirow{4}{*}{ Birth weight (grams) } & $\leq 1000$ & 8 & 4.8 \\
\hline & $1001-1500$ & 36 & 21.8 \\
\hline & $1501-2500$ & 45 & 27.3 \\
\hline & $>2500$ & 76 & 46.1 \\
\hline \multirow{4}{*}{ Gestational age (weeks) } & $\leq 28$ & 6 & 3.6 \\
\hline & 28 weeks 01 day - 32 weeks & 40 & 24.2 \\
\hline & 32 weeks 01 day- 36 weeks & 25 & 15.2 \\
\hline & $>36$ weeks & 94 & 57 \\
\hline \multirow{3}{*}{ APGAR score (at 5 minutes) } & $\leq 3$ & 1 & 6 \\
\hline & 4 to 6 & 24 & 14.5 \\
\hline & $\geq 7$ & 140 & 84.5 \\
\hline \multirow{2}{*}{ Sex } & Male & 97 & 58.8 \\
\hline & Female & 68 & 41.2 \\
\hline \multirow{7}{*}{ Etiology } & RDS & 67 & 40.60 \\
\hline & TTNB & 62 & 37.58 \\
\hline & MAS & 19 & 11.52 \\
\hline & Sepsis & 7 & 4.24 \\
\hline & Birth asphyxia & 5 & 3.03 \\
\hline & Hypoglycemia & 3 & 1.82 \\
\hline & Pneumonia & 2 & 1.21 \\
\hline Requirement of Mechanical ventilation & & 49 & 29.7 \\
\hline \multirow{2}{*}{ Survival/ Mortality } & Survival & 141 & 85.5 \\
\hline & Death & 24 & 14.5 \\
\hline $\begin{array}{l}\text { Respiratory support }\left(\mathrm{O}_{2}, \mathrm{CPAP}, \text { Mechanical Ventilation) }\right. \\
\text { requirement at } 72 \mathrm{hrs} \text { of life }\end{array}$ & & 97 & 58.7 \\
\hline
\end{tabular}


Table 2: Predictors and Mortality

\begin{tabular}{|c|c|c|c|c|c|c|c|c|c|c|c|}
\hline & & \multicolumn{2}{|c|}{$\begin{array}{l}\text { Survival/ } \\
\text { mortality }\end{array}$} & \multirow[t]{2}{*}{ Total } & \multirow[t]{2}{*}{ Sensitivity } & \multirow[t]{2}{*}{ Specificity } & \multirow{2}{*}{$\begin{array}{c}\text { Positive } \\
\text { Predictive } \\
\text { Value }\end{array}$} & \multirow{2}{*}{$\begin{array}{c}\text { Negative } \\
\text { Predictive } \\
\text { Value }\end{array}$} & \multirow{2}{*}{$\begin{array}{l}\text { Odds } \\
\text { ratio }\end{array}$} & \multicolumn{2}{|c|}{$\begin{array}{l}95 \% \text { C.I for } \\
\text { Odds ratio }\end{array}$} \\
\hline & & Survive & Death & & & & & & & Lower & Upper \\
\hline \multirow{2}{*}{$\begin{array}{l}\text { Birth weight } \\
\text { (grams) }\end{array}$} & $>1620$ & 106 & 6 & 112 & $75.18 \%$ & $75.00 \%$ & $94.64 \%$ & $33.96 \%$ & 9.09 & 3.34 & 24.69 \\
\hline & $\leq 1620$ & 35 & 18 & 53 & & & & & & & \\
\hline \multirow{2}{*}{$\begin{array}{l}\text { Gestational } \\
\text { age (weeks) }\end{array}$} & $>31$ & 124 & 8 & 132 & $87.94 \%$ & $66.67 \%$ & $93.94 \%$ & $48.48 \%$ & 14.59 & 5.42 & 39.2 \\
\hline & $\leq 31$ & 17 & 16 & 33 & & & & & & & \\
\hline \multirow{2}{*}{$\begin{array}{l}\text { APGAR } \\
\text { score (at } 5 \\
\text { minutes) }\end{array}$} & $>6$ & 129 & 11 & 140 & $91.49 \%$ & $54.17 \%$ & $92.14 \%$ & $52.00 \%$ & 12.70 & 4.68 & 34.44 \\
\hline & $\leq 6$ & 12 & 13 & 25 & & & & & & & \\
\hline \multirow{2}{*}{$\begin{array}{l}\text { Downe's } \\
\text { score }\end{array}$} & $\leq 3$ & 74 & 2 & 76 & $52.48 \%$ & $91.67 \%$ & $97.37 \%$ & $24.72 \%$ & 12.15 & 2.75 & 53.62 \\
\hline & $>3$ & 67 & 22 & 89 & & & & & & & \\
\hline \multirow{2}{*}{ SpO2 (\%) } & $\leq 86$ & 107 & 8 & 115 & $75.89 \%$ & $66.67 \%$ & $93.04 \%$ & $32.00 \%$ & 6.29 & 2.47 & 15.98 \\
\hline & $>86$ & 34 & 16 & 50 & & & & & & & \\
\hline
\end{tabular}

Table 3: Predictors and mechanical ventilation

\begin{tabular}{|c|c|c|c|c|c|c|c|c|c|c|c|}
\hline & & \multicolumn{2}{|c|}{$\begin{array}{l}\text { Mechanical } \\
\text { ventilation }\end{array}$} & \multirow{2}{*}{ Total } & \multirow{2}{*}{ Sensitivity } & \multirow{2}{*}{ Specificity } & \multirow{2}{*}{$\begin{array}{c}\text { Positive } \\
\text { Predictive } \\
\text { Value }\end{array}$} & \multirow{2}{*}{$\begin{array}{c}\text { Negative } \\
\text { Predictive } \\
\text { Value }\end{array}$} & \multirow{2}{*}{$\begin{array}{l}\text { Odds } \\
\text { ratio }\end{array}$} & \multicolumn{2}{|c|}{$\begin{array}{l}95 \% \text { C.I for } \\
\text { Odds ratio }\end{array}$} \\
\hline & & Required & $\begin{array}{c}\text { Not } \\
\text { required }\end{array}$ & & & & & & & Lower & Upper \\
\hline \multirow{2}{*}{$\begin{array}{l}\text { Birth weight } \\
\text { (grams) }\end{array}$} & $\leq 2000$ & 33 & 36 & 69 & $67.35 \%$ & $68.97 \%$ & $47.83 \%$ & $83.33 \%$ & 4.58 & 2.24 & 9.36 \\
\hline & $>2000$ & 16 & 80 & 96 & & & & & & & \\
\hline \multirow{2}{*}{$\begin{array}{l}\text { Gestational } \\
\text { age (weeks) }\end{array}$} & $\leq 32$ & 27 & 19 & 46 & $55.10 \%$ & $83.62 \%$ & $58.70 \%$ & $81.51 \%$ & 6.27 & 2.96 & 13.23 \\
\hline & $>32$ & 22 & 97 & 119 & & & & & & & \\
\hline \multirow{2}{*}{$\begin{array}{l}\text { APGAR } \\
\text { score (at } 5 \\
\text { minutes) }\end{array}$} & $\leq 7$ & 41 & 43 & 84 & $83.67 \%$ & $62.93 \%$ & $48.81 \%$ & $90.12 \%$ & 8.70 & 3.73 & 20.27 \\
\hline & $>7$ & 8 & 73 & 81 & & & & & & & \\
\hline \multirow{2}{*}{$\begin{array}{l}\text { Downe's } \\
\text { score }\end{array}$} & $>4$ & 26 & 26 & 52 & $59.09 \%$ & $77.39 \%$ & $50.00 \%$ & $83.18 \%$ & 4.94 & 2.35 & 10.39 \\
\hline & $\leq 4$ & 18 & 89 & 107 & & & & & & & \\
\hline \multirow{2}{*}{ SpO2 (\%) } & $\leq 87$ & 28 & 21 & 49 & $57.14 \%$ & $81.90 \%$ & $57.14 \%$ & $81.90 \%$ & 6.03 & 2.88 & 12.6 \\
\hline & $>87$ & 21 & 95 & 116 & & & & & & & \\
\hline
\end{tabular}

Table 4: Predictors and respiratory support at 72 hours of life

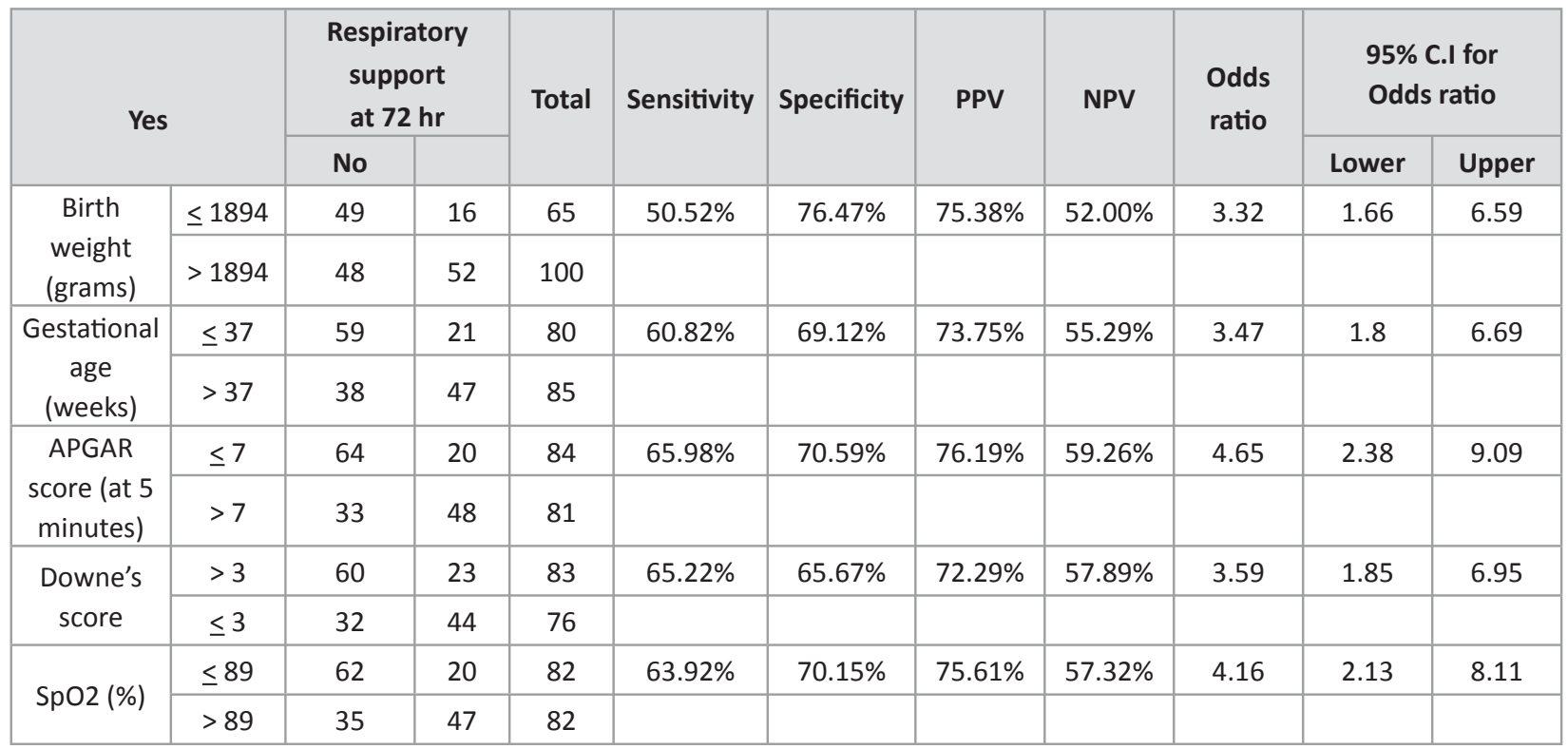




\section{Discussion}

In India, and many developing nations, only few 'Neonatal intensive care units' have level III facilities for newborn care. Most of the centres, especially in the rural districts, have only level II care facilities. Respiratory distress is among the most common symptom complexes seen in the newborn infant. It may result from pulmonary and non pulmonary causes $^{1,2,9,10,11,12,13}$. Prognosis depends not only on the birth weight and gestational age, but also on other perinatal factors and physiological conditions of the individual neonate, in particular the disease severity in the first hours of life $\mathrm{e}^{14,15}$. The prediction of requirement of higher level of care like mechanical ventilation and prolonged requirement of oxygen support is of paramount importance at the peripheral level where sophisticated medical equipments are not available. This study was therefore conducted to assess the utility of birth weight, gestational age, baseline oxygen saturation, Downe's score and APGAR score at $5 \mathrm{~min}$ as predictors of mortality and requirement of respiratory support/ mechanical ventilation at 72 hours in neonates with respiratory distress. In our study, the main causes of respiratory distress requiring mechanical ventilation were Respiratory distress syndrome (61\%) and meconium aspiration syndrome (14\%). The study results are similar to other Indian studies $^{16,17}$. The overall mortality was $14.5 \%$ which was similar to another Indian study by Bhat et al $(18 \%)^{2}$.

\section{Predictors versus defined outcomes:}

Mortality- In our study birth weight of $\leq 1620$ grams was associated with higher mortality (sensitivity $75 \%$, positive predictive value (PPV) $94.64 \%$, Odds ratio (OR)-9, confidence interval (95\% Cl): 3.3-24.6). Our birth weight associated with higher mortality was comparatively lower in value compared to earlier studies done by Mathur et $\mathrm{al}^{18}$ and Malhotra et $\mathrm{al}^{16}$ showing birth weight of $<2000$ gram associated with higher chance of mortality. This shows the trend that with better neonatal care facilities younger neonates are surviving well. Gestation age of $\leq 31$ weeks was predictive of mortality (sensitivity- $88 \%$, PPV- $94 \%$, OR$14.5,95 \% \mathrm{Cl}: 5.42-39.2)$, which is comparable to studies done by Gera et al (30.4 weeks) ${ }^{19}$. Our gestation age cut off value was lesser than as observed by Monir et al (34 weeks) ${ }^{20}$. APGAR score of $\leq 6$ was associated with higher odds of mortality compared to higher scores (sensitivity- 92\%, PPV- 92\%, OR-12.7, 95\% Cl: 4.6-34.4). Our score predictive of mortality was comparable to study by Onama et al (APGAR score $\leq 6)^{21}$ but our value of APGAR score was higher than many previous studies $^{22,23,24,25}$. Downe's score of $>3$ had a sensitivity of $52.48 \%$ with positive predictive value of $97.37 \%$ for mortality. And there was 12.1 times odds $(95 \% \mathrm{Cl}$ : 2.7-53.6) of dying with Downe's score of $>3$. Neonates having oxygen saturation of $\leq 86 \%$ at admission had higher mortality (sensitivity- 76\%, PPV- 93\%, OR-6.29, 95\% Cl: 2.47-15.9). In our study mortality was $49 \%$ in the ventilated neonates which is higher than study by MA Xio et al $(15.4 \%)^{6}$.

Mechanical ventilation-Our study has showed that birth weight of $\leq 2000$ grams is associated with higher requirement of mechanical ventilation (sensitivity-67 $\%$, PPV- 48\%). The odds of requirement of mechanical ventilation with birth weight of $\leq 2000$ grams was 4.58 times (95\% Cl: 2.24-9.36).This was comparable to the study by Mathur et al ${ }^{18}$. Gestation age of $\leq 32$ weeks was predictive of higher requirement of mechanical ventilation (sensitivity- 55\%, PPV- 59\%, OR- 6.27, 95\% $\mathrm{Cl}$ : $2.96-13.23)$. APGAR score of $\leq 7$ had a sensitivity of $83.67 \%$ with positive predictive value of $48.8 \%$ and a high negative predictive value of 90.12 meaning thereby that APGAR score of $>7$ significantly excludes requirement of mechanical ventilation. Eugene et $\mathrm{al}^{26}$ and MA Xiao et $\mathrm{al}^{6}$ also had similar findings with 5 minute APGAR score of $<7$ predicting requirement of mechanical ventilation. In our study Downe's score of $>4$ had sensitivity of $59 \%$ and PPV of $50 \%$ towards predicting ventilator support with an OR of 4.94 (95\% Cl: 2.35-10.39). Baseline oxygen saturation of $\leq 87 \%$ had a sensitivity and PPV of $57.14 \%$ and an OR of $6.03(95 \% \mathrm{Cl}: 2.88-12.60)$ predicting the likely requirement of mechanical ventilation.

Respiratory support (O $\mathrm{O}^{\prime}$ CPAP, ventilation) requirement at 72 hrs of life- Birth weight of $<1894$ grams had higher chances of requiring respiratory support compared to birth weight of > 1894 grams (Odds ratio-3.32, 95\% Cl: 1.66-6.59). The corresponding values for gestational age was 37 weeks (OR-3.47, 95\% Cl: 1.80-6.69), APGAR score-7 (OR-4.65, 95\% Cl: 2.389.09), Downe's score-3 (OR-3.59, 95\% Cl: 1.85-6.95) and baseline oxygen saturation -89\% (OR-4.16, 95\% Cl: 2.13-8.11) .These were associated with requirement of respiratory support at 72 hours with variable sensitivity and specificity as shown in Table 4.

However on multivariate analysis, only gestational age and birth weight were independent predictors of mortality ( $p$-value $<0.05$ ). For requirement of mechanical ventilation, gestation age and APGAR score were independent predictors of ventilation ( $p$-value <0.05). No studied parameter significantly predicted requirement of respiratory support $(\mathrm{O} 2$, CPAP, ventilation) at 72 hours on multivariate analysis. This may have been because of the limited sample size 
or type of sample population which was a limitation of the study.

\section{Conclusion}

Neonatal respiratory distress is one of the common causes of NICU admission in India and other developing countries. Illness severity assessment is important for the management. The APGAR score, Downe's score and $\mathrm{SpO} 2$ monitoring can be done non invasively with relative ease. The suggested cut offs for the observed (Birth weight and gestation age) and monitored (Downe's score, APGAR score and oxygen saturation) parameters may be together used to predict the requirement of respiratory support, mechanical ventilation and mortality in neonates with respiratory distress thereby guiding the decisions for treatment of these babies in a given neonatal care facility as against referral to a higher centre.

\section{Acknowledgements: Nil \\ Conflict of Interest: Nil \\ Funding: None \\ IRB clearance: Cleared}

\section{References}

1. "National neonatal perinatal database". Report for the year 2002-2003. National Neonatology Forum, India

2. Kumar A and Bhat V. Epidemiology of Respiratory Distress of newborn. Indian J Pediatr 1996; 63: 9398.

3. Downes JJ, Vidyasagar D, Boggs TR Jr, Morrow GM. Respiratory distress in newborn infants; new clinical scoring system with acid base and blood gas correlations. Clin Pediatr (Phila) 1970;9(6):32531.

4. Silverman WC, Anderson DH. Controlled clinical trial on effects of water mist on obstructive respiratory signs, death rate and necropsy findings among premature infants. Pediatrics 1956;17:1-4.

5. Apgar V. A Proposal for a New Method of Evaluation of the Newborn Infant. Curr Res Anesth Analg 1953;32(4):260-67.

6. MAXiao-lu, XuXue-feng, Chen C,etal. Epidemiology of respiratory distress and the illness severity in late preterm or term infants: a prospective multicenter study. Chin Med J 2010;123(20):2776-780.

7. The CRIB (Clinical risk index for babies) score: a tool for assessing initial neonatal risk and comparing performance of neonatal intensive care units. The International Neonatal Network. Lancet 1993;342:193-98.

8. Richardson DK, Phibbs CS, Gray JE, et al. Birth weight and illness severity: independent predictors of neonatal mortality. Pediatrics 1993;91:969-75.

9. Mathai SS,Raju U, Kanitkar M. Management of respiratory distress in the newborn. Med J Armed Forces India 2007; 63:269-72.

10. Hameed NN, Al-Janabi MK, Al-Reda YI. Respiratory distress in full term newborn; Iraqi Postgraduate Med J 2007; 6(3): 233-39.

11. Khatua SP, Gangwal A, Basu P, Patodhi PKR. The incidence and etiology of respiratory distress in newborn. Indian Pediatr 1979;16:1121-126.

12. Misra PK. Respiratory distress in newborn. Indian Pediatr 1987; 24: 77-80.

13. Agrawal V, David RJ, Harris VJ. Classification Of Acute Respiratory Disorders Of All Newborns In A Tertiary Care Center. J Natl Med Assoc 2003;95:585-595.

14. Swietlinski J, Bachman T, Gajewska E, Bober K, Helwich E, Lauterbach R, Maruszewski B, Szczapa J, Skrzypek M; Polish Non-invasive Respiratory Study Group.Factors affecting outcomes in very low birth weight infants treated electively with nasal continuous positive airway pressure. J Perinatol 2010;30(2):112-17

15. Brix $N$, Sellmer A, Jensen MS, Pedersen LV, Henriksen TB1. Predictors for an unsuccessful INtubationSURfactant-Extubation procedure: a cohort study. BMC Pediatrics 2014;14:155

16. Malhotra A K, Nagpal R, Gupta R K, Chhajta D S, Arora R K. Respiratory Distress in Newborn: treated with ventilation in level- II nursery. Indian J Pediatr 1995;32:207-11.

17. Nangia S, Saili A, Dutta AK et al. Neonatal mechanical ventilation, experience at level 2 care centre. Indian J Pediatr 1998;65:291-1998;65:29196.

18. Mathur NB, Garg K, Kumar S. Respiratory distress in neonates with special reference to pneumonia. Indian Pediatr 2002;39:529-37.

19. Gera T, Ramji S. Early predictors of mortality in very low birth weight neonates. Indian Pediatr 2001;38:596-602.

20. Hossain MM,Shirin M,Al-Mamun MA,Hasan MN,Sahidullah M. Predictors of Mortality in Ventilated Neonates in Intensive Care Unit. Bangladesh J Child Health 2009; 33(3):77-82. 
21. Ondoa-Onama C, J K Tumwine JK. Immediate Outcome Of Babies With Low Apgar Score In Mulago Hospital, Uganda. East Afr Med J 2003;80(1):22-29.

22. Clark RH . The Epidemiology of Respiratory Failure in Neonates Born at an Estimated Gestational Age of 34 Weeks or More. J Perinatol 2005; 25: 251257.

23. Rubaltellia FF, Bonafèb L, Tanguccic M, Spagnoloc A, Dania C, and the Italian Group of Neonatal Pneumology. Epidemiology of Neonatal Acute Respiratory Disorders A Multicenter Study on Incidence and Fatality Rates of Neonatal Acute Respiratory Disorders According to Gestational
Age, Maternal Age, Pregnancy Complications and Type of Delivery. Biol Neonate 1998;74:7-15.

24. Basu S,Rathore P,Bhatia BD. Predictors of mortality in very low birth weight neonates in India. Singapore Med J 2008;49(7):556-60.

25. Lee HC,Subeh M,Gould JB. Low Apgar Score and Mortality in Extremely Preterm Neonates Born in the United States. Acta Paediatr 2010;99(12):1785-789.

26. Salustiano EMA, Campos JAD, Ibidi SM, Ruano R, Zugaib M. Low Apgar scores at 5 minutes in a low risk population: maternal and obstetrical factors and postnatal outcome. Rev Assoc Med Bras 2012; 58(5):587-93. 